\title{
Chronostratigraphic study of the Grottaperfetta alluvial valley in the city of Rome (Italy): investigating possible interaction between sedimentary and tectonic processes
}

\author{
Francesca R. Cinti $\left({ }^{1}\right)$, Fabrizio Marra $\left({ }^{1}\right)$, Francesca Bozzano $\left({ }^{2}\right)$, Fabrizio Cara $\left({ }^{1}\right)$, \\ Giuseppe Di Giulio $\left.{ }^{(}\right)$and Enzo Boschi $\left({ }^{1}\right)$ \\ (1) Istituto Nazionale di Geofisica e Vulcanologia, Roma, Italy \\ $\left.{ }^{(}\right)$Dipartimento di Scienze della Terra, Università «La Sapienza», Roma, Italy
}

\begin{abstract}
We carried out geomorphologic and geological investigations in a south-eastern tributary valley of the Tiber River in Rome, the Grottaperfetta valley, aimed to reconstruct its buried geometry. Since results of the geomorphologic study disclosed anomalies of the stream beds, we performed geoelectric and boreholes prospecting to check whether recent faulting, rather than an inherited structural control, possibly contributed to the evolution of the alluvial valley. Vertical offsets of the stratigraphic horizons across adjacent boreholes were evidenced within the Late Pleistocene-Holocene alluvium and its substratum. In order to rule out the effects of irregular geometry of the alluvial deposits, we focussed on sectors where vertical offsets affected all the stratigraphic horizons (alluvium and pre-Holocene substratum), showing an increasing displacement with depth. We identified a site where repeated displacements occur coupled with a lateral variation of soil resistivity, and we drilled an oblique borehole aimed to cross and sample the possible fault zone affecting the terrain. A $7 \mathrm{~cm}$ thick granular layer, inclined $50^{\circ} \div 70^{\circ}$ on the horizontal, was recovered $5 \mathrm{~m} \mathrm{b.g}$., and interpreted as the filling material of a fracture. The convergence of the reported features with independent evidence from geoelectric and geomorphologic investigations led us to hypothesize the presence of a faulting zone within the Holocene alluvial terrains and to propose the excavation of a trench to verify this hypothesis.
\end{abstract}

Key words Holocene stratigraphy - recent tectonics - Tiber valley Rome

\section{Introduction}

Dealing with active tectonics in highly urbanized areas is always a delicate task, since it has several strong direct and indirect implications. The identification of a fault affecting re-

Mailing address: Dr. Francesca R. Cinti, Istituto Nazionale di Geofisica e Vulcanologia, Via di Vigna Murata 605, 00143 Roma, Italy; e-mail: cinti@ingv.it cent deposits will induce a variation in the possible use of the land and therefore its economic value, and it has also a significant social impact with respect to the inhabitants of the near-fault buildings.

When not directly exposed in an outcropping terrain, the identification of a fault may be achieved through the analysis of stratigraphic or morphologic indicators. Ultimately, the identification of a fault, and the collection of elements useful to establish its potential activity, needs a direct investigation of the stratigraphy at depth, usually in the form of a trench excavation (see Mc Calpin, 1996). However, common 
approaches in fault investigation may be handicapped if applied in urbanized area, where no direct and continuous observation of the original ground surface may be available, and no outcrops of pristine rock may be found. In such cases, the characteristics of the lithology, subsurface structure and fault zone can be inferred from direct borehole drilling data. Through the correlation of boreholes data, cross-sections can be drawn to outline the subsurface geology of the site, which will be more detailed and realistic the more boreholes are close to each other. Recognition of vertical offsets in the stratigraphic succession is a first step to identify possible tectonic dislocation, although there is no certainty whether the observed offset is a depositional feature or is caused by a fault displacement. A possible criterion that helps to discriminate between the two possibilities is the occurrence of increasing displacement with depth within subsequent strata of the sequence. However, this observation is also not decisive. This paper describes a method that allows the inferred fault zone to be reached and sampled, through the analysis of the core sample obtained by drilling an oblique borehole across the subsurface structure.

Following this line, we illustrate the study we performed in the city of Rome, in an area aimed to reconstruct a series of buildings of the 50 's-60's, that are going to be demolished having suffered damage from differential settling. Several technical reports concluded that the damage was caused by inadequate foundations above alluvial soft soils (www.urbanistica. comune.roma.it/giustinianoimperatore/il_quartiere-caratteristiche.html).

\section{Geologic and geomorphologic setting of the city of Rome}

The city of Rome is located on the margin of the Central Tyrrhenian Sea (fig. 1), where the general NW-SE structural trend of the Southern Apennine chain is interrupted by the N-S oriented external thrust fronts of the Northern Apennine chain (inset in fig. 1). A NW-SE belt of undersaturated, potassic volcanoes developed during Middle Pleistocene along the Tyr- rhenian Sea margin (Serri, 1997; Marra et al., 2004a), parallel to the major extensional faults originated by back-arc extension that induced the opening of the Tyrrhenian Basin (Locardi et al., 1977). The area of Rome has been characterized by marine sedimentary condition since Pliocene through Early Pleistocene times. Thereafter, around $900 \mathrm{ka}$ a delta of the paleoTiber River firstly developed (Karner et al., 2001). During Middle-Late Pleistocene and Holocene times the sedimentary processes in the area of Rome were restricted into the fluvial channels and coastal plain and were strongly controlled by sea-level changes linked to glacio-eustatism (Karner and Renne, 1998; Karner and Marra, 1998). During the last 800 ka strong tectonic activity, associated with the development of two large volcanic districts (the Monti Sabatini and the Alban Hills) occurred in this region, acting mainly through vertical movement. Three major phases of regional uplift associated with volcanism occurred around 800 kyr, $600 \mathrm{kyr}$ and $250 \mathrm{kyr}$, causing a paleogeographic change in the area of Rome (Karner et al., 2001). The tectonic activity was likely expressed through the re-activation of pre-existing discontinuities as well as new fault displacements that controlled the geometry of the hydrographic network. Indeed, several works in the area of Rome (Caputo et al., 1995 and references therein, Marra, 1999; 2001) attributed the $\mathrm{N} 140^{\circ} / \mathrm{N} 180^{\circ}$ preferential directions of the stream-beds to a tectonic control on the hydrographic network. However, it was commonly interpreted to reflect an inherited geometric pattern of inactive faults. More recently, structural geologic and archaeological investigations have re-evaluated the possibility that tectonic activity occurred in historical times in the area of Rome (Marra et al., 2004b).

Figure 1 shows that a well defined drainage network is present in the area of Rome, where the Late Pleistocene-Holocene alluvial valleys display prominent and steep banks bordering the floodplains. The regional uplift of $\sim 40 \mathrm{~m}$ that occurred in the last $250 \mathrm{ka}$ (Karner et al., 2001) was the concomitant cause for rejuvenating and sharpening the morphological features of the hydrographic network. At each glacial maximum in the last two marine isotopic stages 


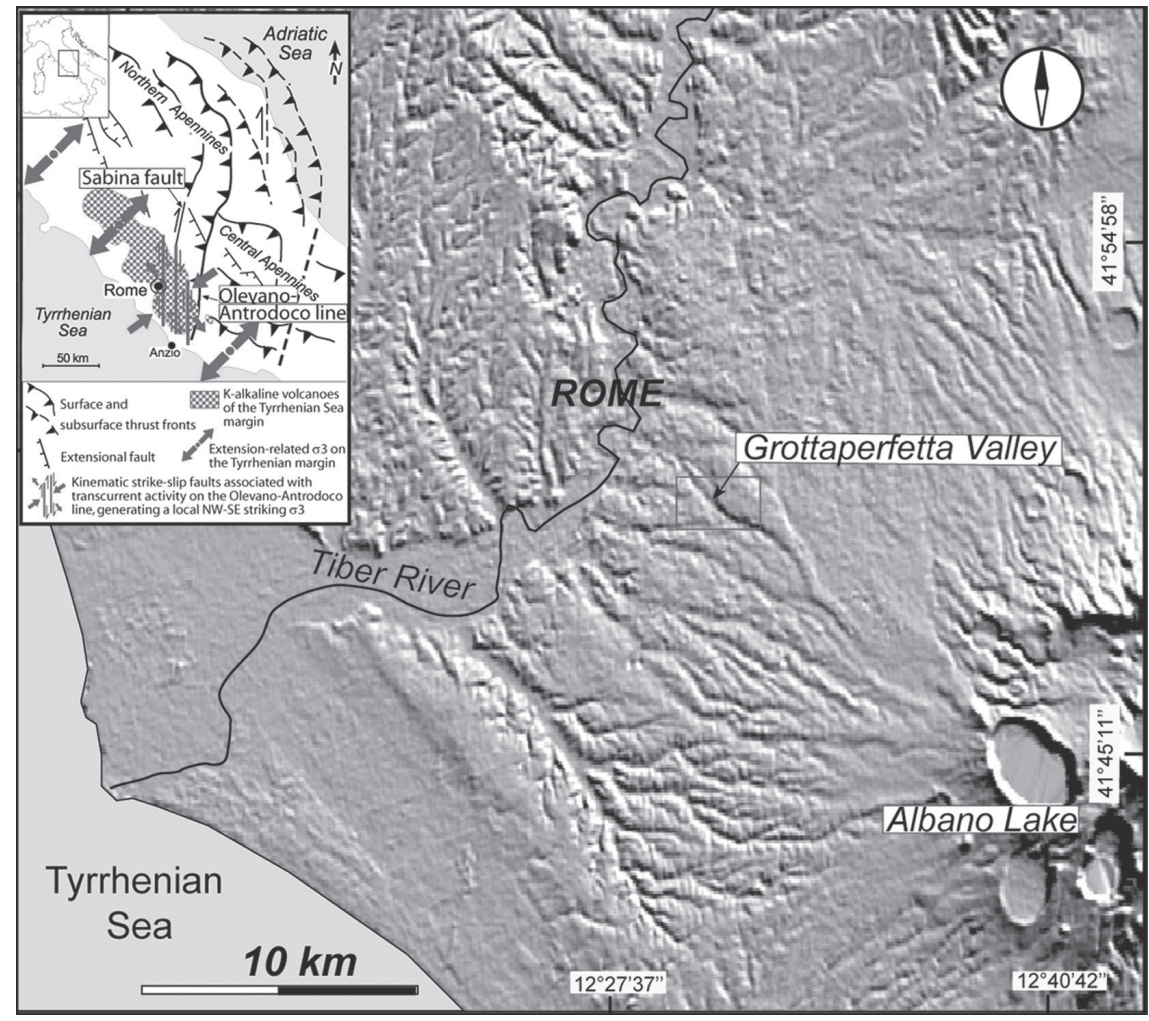

Fig. 1. Shaded relief of the area of Rome showing the morphology related to the hydrographic network of the Tiber River and its tributaries. The studied valley of Grottaperfetta is indicated. The inset shows a schematic structural map of Rome and surrounding region (modified from Marra et al., 2004a).

8 and 6 , the valleys were excavated deeper than during the previous ones, and the subsequent sea-level rises associated to the high-stands could account only for partial filling of the incisions originated during the erosive phases.

These marked features of the fluvial incisions are partially obliterated in the urban area, where more than 2,000 years-long anthropic activity strongly modified the original morphology.

\section{Geomorphologic features of the Grotta- perfetta valley}

The Grottaperfetta valley is a left tributary of the Tiber River (fig. 1) that flows for a total length of about $7 \mathrm{~km}$ with a SE-NW average direction. It develops in two distinct sections with subparallel direction (valleys 4 and 1 in fig. 2a) and that are laterally offset of about 500 $\mathrm{m}$. The alluvial plain reaches a maximum width of $300 \mathrm{~m}$ in the section proximal to the junction with the Tiber River. Nowadays the original stream-bed is no more visible, since it has been completely channelled and connected to the sewer system of the city. The alluvial plain itself is mostly urbanized and covered by buildings and roads (fig. 3).

The Grottaperfetta valley, like most of the Tiber River's hydrographic network, originated since the times of upwelling and continentalization of the area of Rome, and was deepened during each glacial epoch until the last one (Würm, 18-20 ka). It is likely, however, 

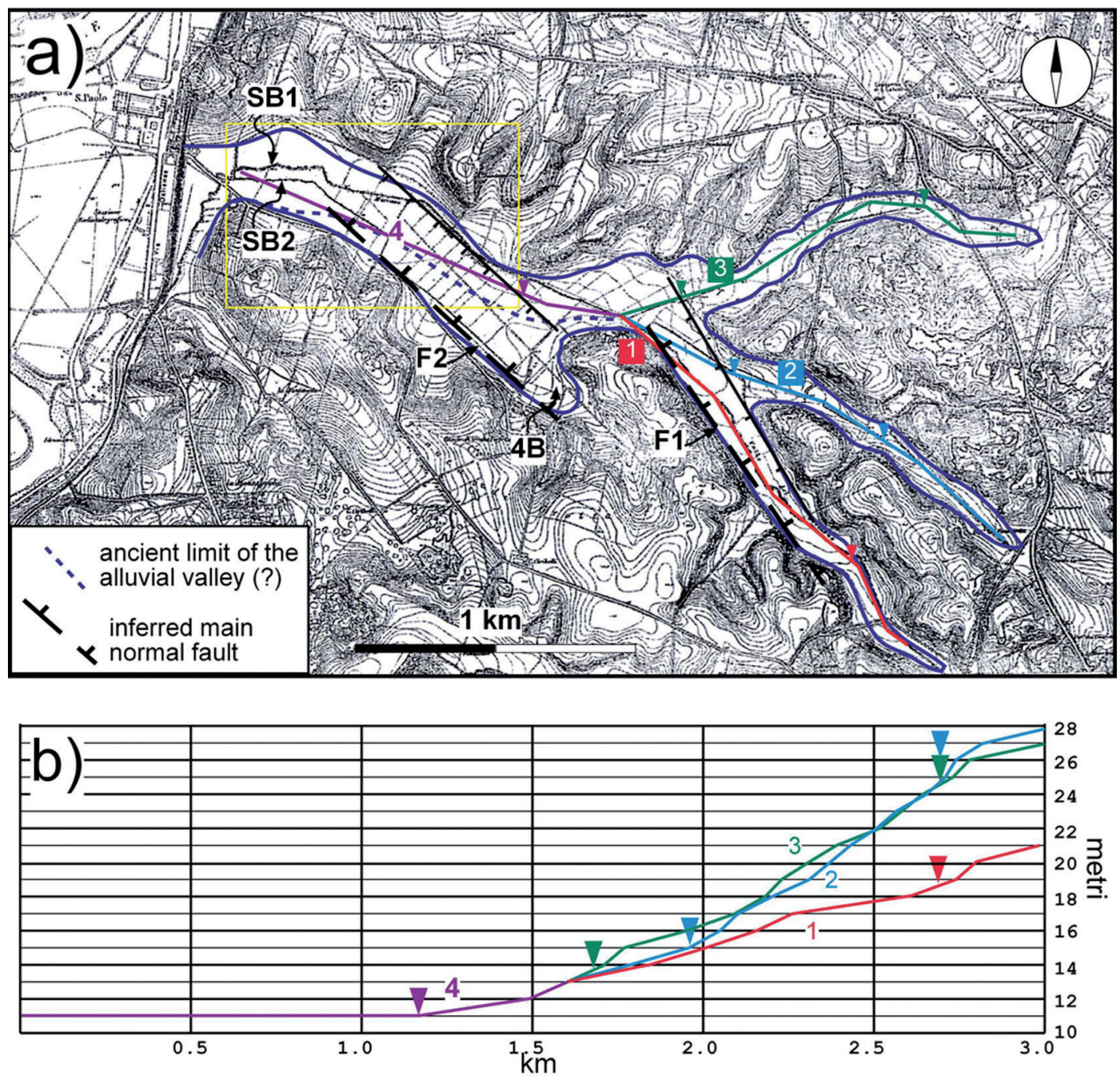

Fig. 2a,b. The Grottaperfetta alluvial valley and the inferred fault traces bounding the south western edge (F1 and F2); rectangle includes the area enlarged in fig. 3. SB1 and SB2 indicate two convergent stream-beds. The profiles referred to different sectors of the alluvial valley are numbered as 1,2,3,4 and 4B and reported in fig. 2b. Coloured triangles mark the sharp vertical changes occurring along the profiles.

that tectonic activity occurring in this time span controlled the geometry of the hydrographic network and repeatedly modified several stream-beds direction (Marra, 2001). During the Last Glacial Maximum the sea level lowering (more than $120 \mathrm{~m}$ ), combined with $25 \mathrm{~m}$ of uplift with respect to the previous low-stand period (Karner and Marra, 1998), caused a deeper incision of the fluvial valleys in the area of the city of Rome, cutting also the bedrock down to $60 \mathrm{~m}$ below the present sea level (Marra and Rosa, 1995). Following the re-establishment of temperate climatic conditions, the relatively fast rise of the sea 


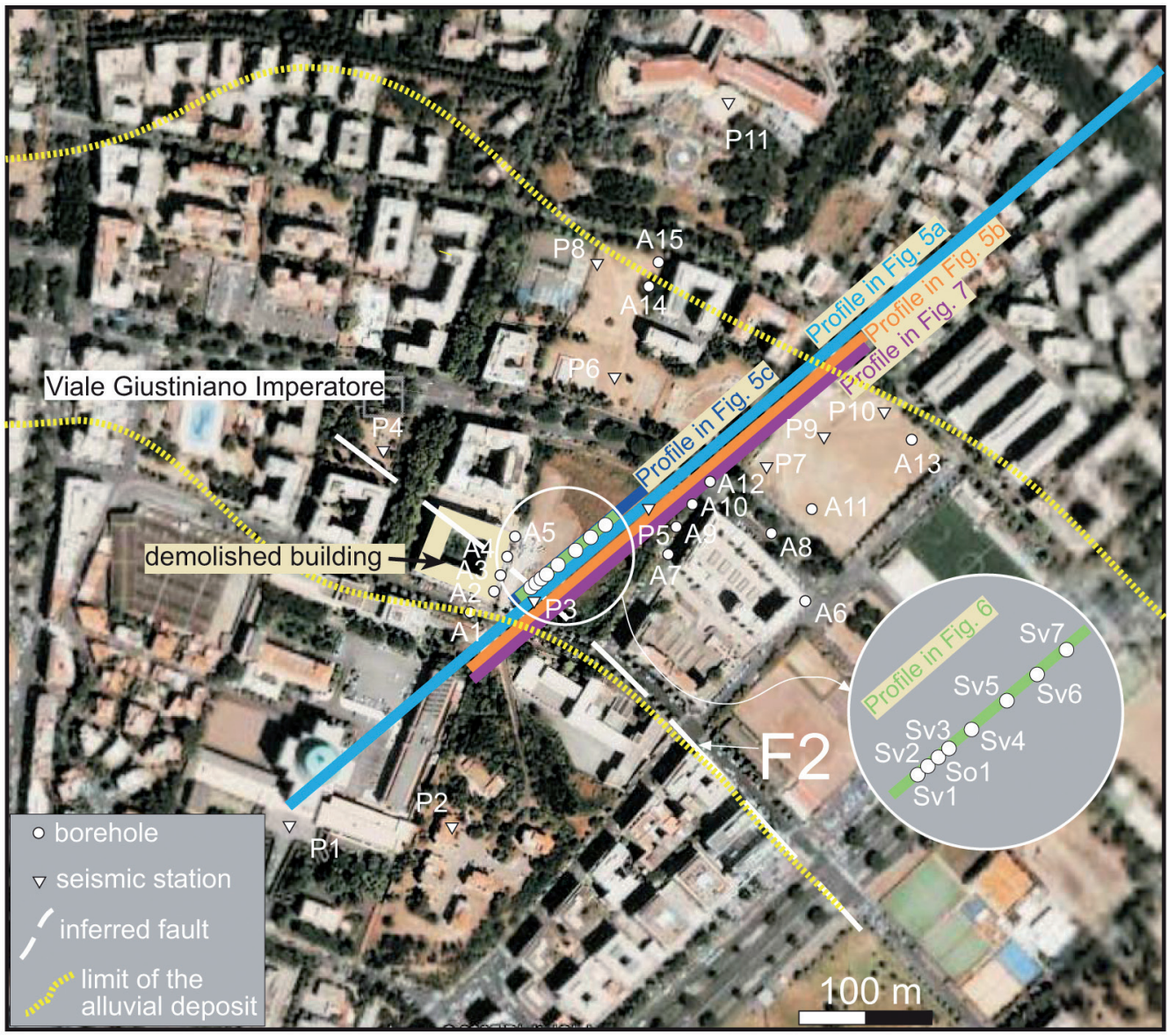

Fig. 3. Location of the geoelectric profile (blue line) and of the boreholes campaign performed in this study (Sv1-Sv7, So1, see the enlargement in the circle). The setting of the INGV seismic stations (P1-P11) at the Grottaperfetta valley and the location of boreholes whose logs were acquired from different sources (A1-A15) are also shown.

level (Bard et al., 1996) induced the consequent filling of the fluvial incisions up to the present level of deposition. The sediments deposited during Late-Pleistocene-Holocene times within the incisions are generally characterized by a fining-upward succession, with a relatively thin horizon of gravel at the base grading into a thick pack of sand and clay (Bozzano et al., 2000). Within this sedimentary body it is frequent the intercalation of organic material such as carbonized plants and peat horizons.

\subsection{Geomorphologic observations and interpretation}

The higher and eastern portion of the Grottaperfetta hydrographic network consists of three convergent stream valleys $(1,2$ and 3 in fig. 2). The northernmost two valleys (2 and 3 ) appear suspended with respect to the southern one (1). In particular, despite the similar length, a steeper gradient characterizes the floodplain of the northern valleys (fig. 2b) up to their confluence into the southern one ( 1 in fig. 2). Moreover 
at this site, a sharp gradient (see triangles in fig. $2 b$ ) variation of the profile of the valleys occurs. An abrupt change is also recorded along the profile of valley 4 in proximity of the confluence of the three eastern valleys. The western portion of the alluvial plain enlarges and elongate to the SE (4B), and in its final portion two stream-beds are present (SB1 and SB2 in fig. 2a).

We interpret the described elements as the effects of an inherited tectonic control, associated with the activity of a NW-SE fault system that repeatedly vertically deformed the area (fig. 2a). The peculiar setting of valleys 1,2 and 3 fits with a more recent, tectonic origin (or rejuvenation) of the southern stream-bed (1) with respect to the northern ones ( 2 and 3$)$, as an effect of its recent lowering due to the activity of two synthetic NW-trending faults (F1, fig. 2a). A similar process is inferable in the western portion of the Grottaperfetta valley (4 in fig. 2), where another NW-trending main and antithetic fault segments (F2, fig. 2a) might be responsible for producing the subsidence of this portion of the valley and the axis deviation of the stream-bed. Moreover, excluding undocumented anthropic modification, the enlargement, the SE elongation of the western sector of the alluvial plain, as well as the two stream-beds in its final portion, may be interpretable as a tectonic effect generated under the regional NESW extensional regime (Montone et al., 1995).

\section{Subsurface features of the Grottaperfetta valley}

\subsection{Geophysical investigations}

Seismic noise measurements were performed in the Grottaperfetta valley by researchers of the INGV (project within http://sesamefp5.obs.ujf-grenoble.fr/SES_Reports.htm). Following the Nakamura technique (Nakamura, 1989), the resonance frequency at a site was empirically determined from the spectral ratio of the horizontal and vertical component $(\mathrm{H} / \mathrm{V})$ of the recorded seismic noise. In the valley, only three stations (P4, P5, P6; figs. 3 and 4a) showed the frequency peak around $1 \mathrm{~Hz}$ expected for $\mathrm{a} \sim 50 \mathrm{~m}$ pack of soft sediments (as- suming a $\mathrm{V}_{\mathrm{s}}$ of about $200 \mathrm{~m} / \mathrm{s}$; Martino et al., 2004), out of eight that were located above the alluvial sediments. With respect to what was expected from the width of the valley estimated by surface geology and previous borehole investigations, seismic noise data suggested a shift toward south of the deepest portion of the incision, where is the maximum thickness of the sediments (dashed line in the cross section of fig. 4a). This is due to the fact that a sediment thickness $\geq 30 \mathrm{~m}$ is estimated from measured spectral ratios only in correspondence of $\mathrm{P} 4$ and $\mathrm{P} 5$, but not in correspondence of P6 and P7, which are located symmetrically with respect to the central axis of the valley, as inferred from surface geology.

The borehole stratigraphic logs already available in the area (from the database of stratigraphic logs of the Roman area by INGV) were used to trace a schematic cross-section of the valley at the Viale Giustiniano Imperatore site (fig. 4b). The correlation of the borehole data showed several discontinuities of the stratigraphic boundaries pertaining to the base of the alluvial deposit and to the main sedimentary units, with vertical offsets between two tracts showing a quite regular trend. However, since lateral discontinuity is a common feature for the fluvial sediments, we focused our attention on two adjacent stratigraphic logs (A4, A5, fig. 4b). Across these two borecores, the gravel layer (GL, fig. 4b) that is part of the pre-Holocene substratum of the valley, and that elsewhere showed sub-horizontal attitude, records a significant vertical separation. When combined with the thickness of the alluvial sediments inferred from the seismic noise data, particularly at station P4 (see fig. $4 a, b)$, a possibly asymmetric shape of the transversal profile of the valley was outlined.

We performed geoelectrical profiles across the southern sector of the valley, where the major horizontal discontinuity appeared (fig. 4c). The results disclosed zones of resistivity discontinuity suggesting persisting lateral variation in the subsurface setting. One of these zones occurs at the projection of the inferred fault between logs A4 and A5 (fig. 4b, c).

Among several possible interpretations for the vertical separation of GL unit observed across borecores A4-A5 and the zone of resis- 
tivity discontinuity observed at the same site, a faulting process on the alluvial deposits could not be discarded (fig. 4b). The circumstances grow much suspect when one realizes that the continuation of the supposed fault bordering the south bank of the valley (F2, figs. $2 \mathrm{a}$ and 3 ), as inferred from the geomorphologic analysis, crosses between the two boreholes.

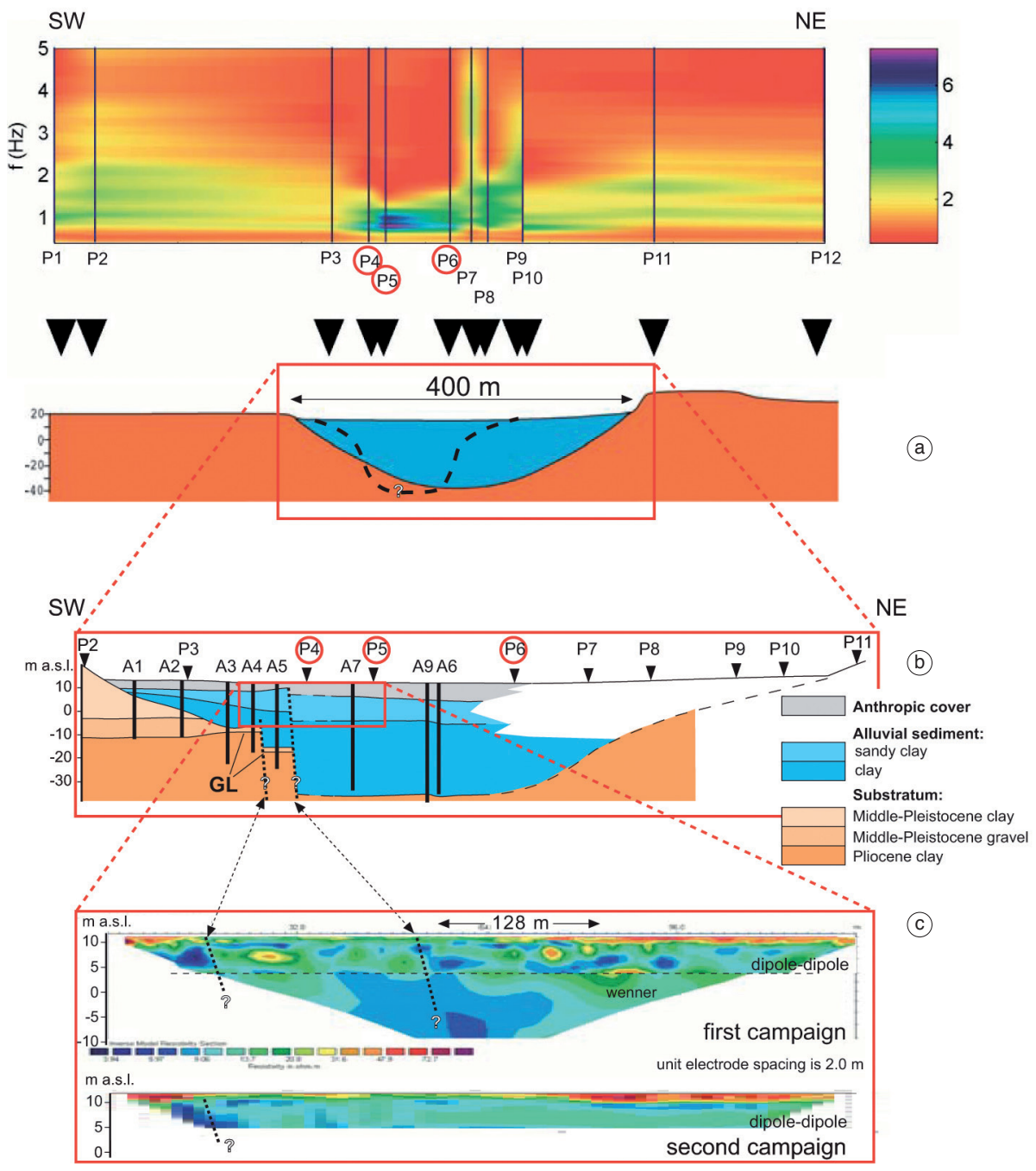

Fig. 4a-c. a) Results of the seismic noise measurements from the INGV seismic array at the Grottaperfetta site (see fig. 3 for location of the seismic stations) showing the amplification frequencies of the H/V ratio across the valley. The dashed line in the inferred geological cross-section evidences the asymmetric shape of the valley, as suggested from the position of the highest peaks along the section. b) Schematic geological reconstruction of the asymmetric valley based on acquired stratigraphic logs of boreholes (see fig. 3 for locations). c) Inversion from geoelectrical profile across the valley (for location see blue line in fig. 3) performed with different arrays. The second campaign provided more reliable data for the upper portion of the alluvial fill. Black dotted lines are positioned where lateral variations of the resistivity of the sediments are suggestive of the presence of a fault. 


\subsection{Boreholes data}

We performed a drilling survey in a portion of the valley where the above mentioned anomalies were recognized (fig. 4b). Eight boreholes
(Sv1-Sv7, So1, fig. 3), reaching 8.5 to $50 \mathrm{~m}$ of depth, allowed us to reconstruct an $80 \mathrm{~m}$ long, transversal geologic section across the southern half-length of the Grottaperfetta valley (fig. 5). The section is perpendicular to the stream
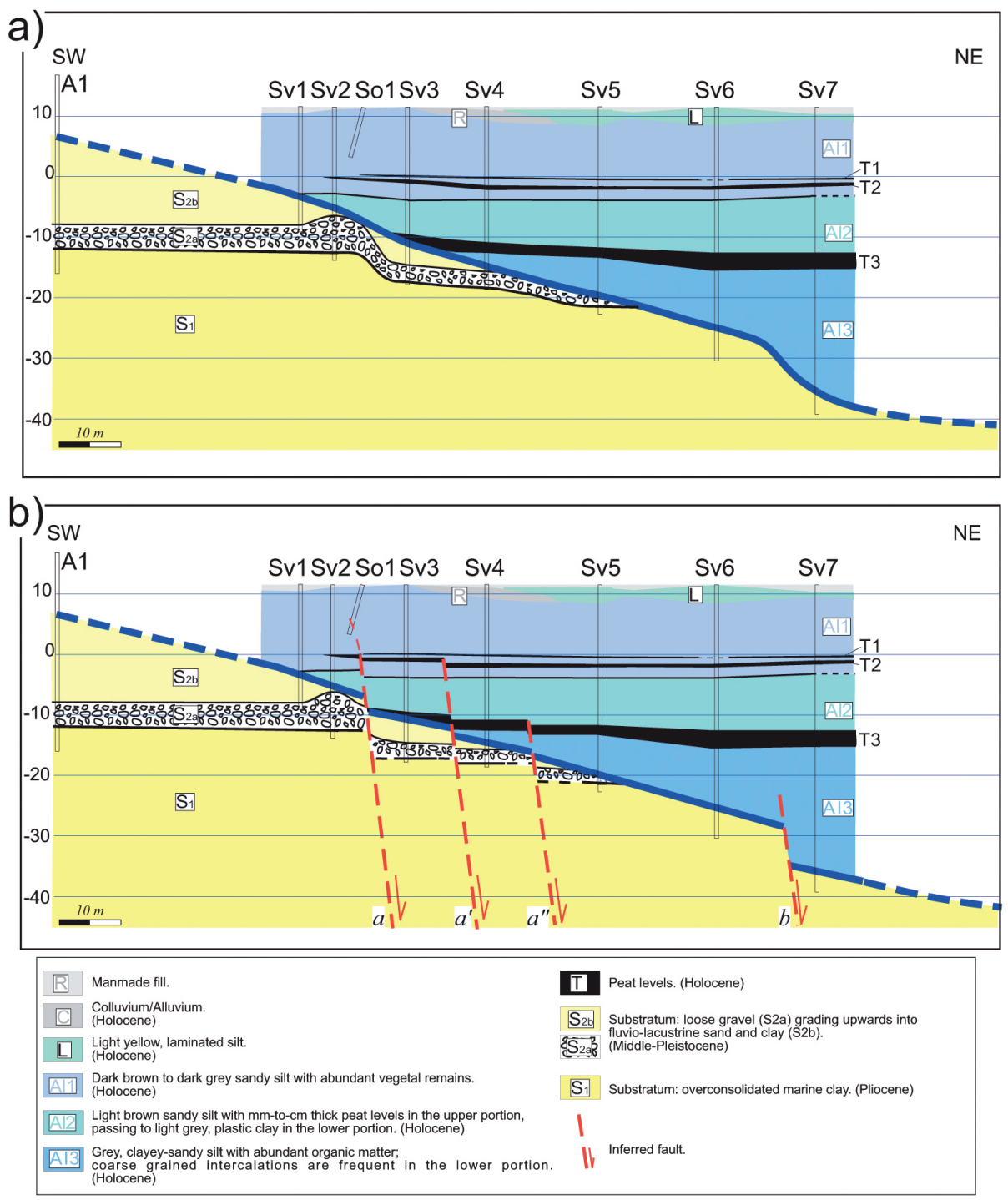

Fig. 5a,b. Detailed stratigraphic cross-section of the southern portion of the Grottaperfetta valley reconstructed by means of boreholes performed for this study (Sv1-Sv7, So1). One acquired stratigraphic log (A1) is also used to constraint the edge of the incision (see fig. 3 for location). a) Uninterpreted profile. b) Interpreted profile: changes in elevation of the stratigraphic limits are associated to fault displacement. 
course and spans from a point close to the southern edge of the valley to its central axis. Seven boreholes reached the pre-Holocene substratum of the valley at increasing depth from $\mathrm{S}$ to $\mathrm{N}: 15 \mathrm{~m}$ to $46.6 \mathrm{~m}$ below the ground surface, corresponding to $3.5 \mathrm{~m}$ to $35 \mathrm{~m}$ below the sea level (fig. 5). The substratum is constituted by a succession of Pliocene marine clay sediments (S1; Monte Vaticano Unit, Marra and Rosa, 1995), followed by transgressive fluvial-lacustrine deposit (S2a-2b, Paleotiber Unit, Marra and Rosa, 1995) of Middle Pleistocene. The latter is represented here by a basal layer of loose coarse gravel, about $5 \mathrm{~m}$ thick, grading upwards into sand, silt and clay. This continental sequence is eroded in the deeper portion of the Grottaperfetta incision, where the Late Pleistocene-Holocene deposits directly overlie the marine Pliocene substratum. The Monte Vaticano Unit is locally represented by an alternating succession of decimeter-thick horizons of clay and silty-sand; according to Bozzano et al. (1995) it is very consistent and is characterized by Over Consolidation Ratio (OCR) $>5$ and low compressibility. The Middle-Pleistocene sandy-clayey sediments of the Paleotiber Unit are also characterized by medium-high consistency, whereas the Late Pleistocene-Holocene deposit is represented by low consistency silty clay and sandy silt. In surrounding areas, alluvial deposits are resulted from normally consolidated to weakly overconsolidated, satu- rated in water, and are characterized by low deformability moduli (Bozzano et al., 2000). A coarser granulometric fraction occurs in the lower portion of the alluvial succession, where frequent layers of fine gravel are intercalated to the sandy silt sediments. Abundant organic matter is also present throughout the alluvium, either as diffuse fragments of vegetal remains, as well as mm-to-dm thick peat levels.

Based on the homogeneous lithologic features, three main sedimentary horizons (Al1, Al2, Al3; fig. 6) can be identified within the alluvial body. An upper sedimentary horizon (L) of yellow sandy silt is present in the northern portion of the section. Based on its stratigraphic position and on the occurrence of fragments of baked clay, it is interpreted to be a lacustrine deposit of historical time. Pottery and brick fragments are also found in the upper alluvial horizon down to a depth of $10 \mathrm{~m}$, dating back to approximately 3,000 years BP (see the following text). Three peat levels (T1, T2, T3) of significant thickness (from several $\mathrm{cm}$ to 2-3 m) are also identified throughout the section. Finally, a shallow cover of manmade fill (R) showing discontinuous thickness ( 0.35 to 3.0 $\mathrm{m})$ is present above the recent alluvial sediments along the investigated section.

A detailed sedimentary and geochronologic analysis has been carried out on the alluvial deposits recovered by the adjacent boreholes SV6 and SV7. Radiocarbon datings on nine

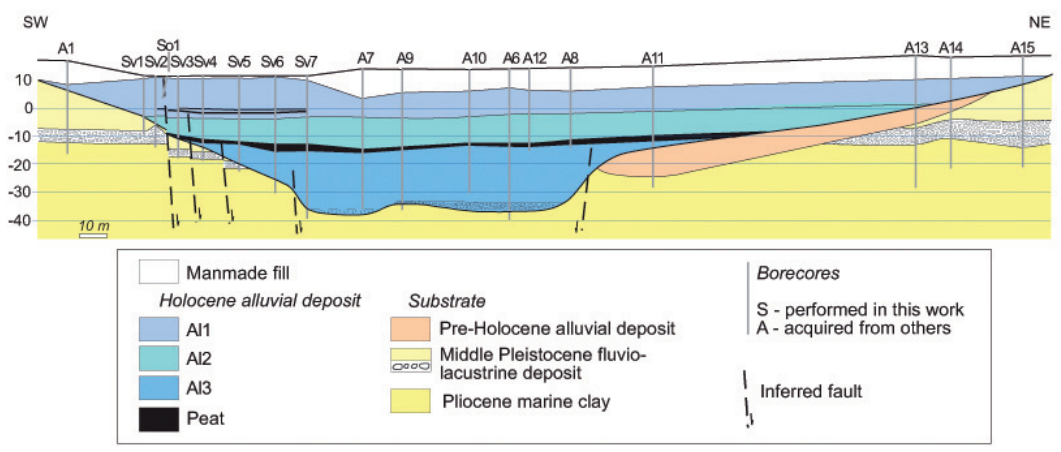

Fig. 6. Cross-section of the Grottaperfetta valley reconstructed through the integration of the boreholes stratigraphic logs (see fig. 3 for location) from this study (Sv1-Sv7 and So1) and the acquired dataset of boreholes (A1-A15). 
core samples containing organic matter (either in form of peat, wood or sediment) have been performed by the Beta Analytic Laboratory, Florida, U.S.A. (table I).

Unit Al3 was the first deposit filling the valley starting since the end of the last glacial maximum, as testified by the $\mathrm{C} 14$ age of the organic material collected at the base of this unit in borehole Sv7 (see also fig. 7a). In the light of the commonly accepted start of the sea level rise at about $18 \mathrm{kyr}$ (Bard et al., 1996), the age of $16.84 \pm 0.40 \mathrm{kyr}$ of sample $\mathrm{C} 1$ and the absence of a gravel level at the base of $\mathrm{Al} 3$ in Sv7 are consistent with the fact that this borehole did not reach the deepest and central portion of the alluvial sedimentary body. Indeed, a level of coarse gravel at the base of the alluvial sequence is found in the stratigraphic logs of different boreholes at a slightly major depth with respect to Sv7 (around $-36.5 \mathrm{~m}$ b.s.l. in A9 and A6 respectively, fig. 6), and located in correspondence of the central axis of the valley.

The peat level T3 was systematically collected in boreholes Sv3, Sv4, Sv5, Sv6 and Sv7, and it was also identified in several other acquired stratigraphic borehole logs (fig. 6), at depths between $21 \mathrm{~m}$ and $24 \mathrm{~m}$ below the ground surface. This unit marks the transition between the distinct alluvial deposits $\mathrm{Al} 3$ and $\mathrm{Al}$. The radiocarbon age of the peaty deposit was within $8810 \pm 210 \mathrm{BP}$ and $8400 \pm 60 \mathrm{BP}$.
Unit Al2 includes a $6 \mathrm{~m}$ thick layer of lightgrey, unconsolidated clay without organic matter. This layer passes upwards to a $2 \mathrm{~m}$ thick, dark-grey-to-brown clay horizon, enriched in organic matter.

Al1 is the upper alluvial unit, showing significant different feature with respect to the previous unit. It is a light brown sandy deposit with abundant reworked pyroclastic material and sparse vegetal remains. Two peat layers (T1 and T2) occur in the lower portion of this unit and have been recovered in all the borecores. Two samples from Sv3 (C9 and C8) have been dated at $3450 \pm 60$ and $5040 \pm 70$ B.P. (table I), constraining the age of All and evidencing a drastic decrease in the sedimentation rate within the Grottaperfetta valley in the time span 6000-3500 BP.

\section{Data interpretation}

\subsection{The vertical offsets along the cross- section}

The overall reconstructed geologic setting throughout the investigated portion of the Grottaperfetta Valley shows lateral variations in the elevation of different stratigraphic boundaries (fig. 5), consistent with a general decrease in elevation from the bank toward the center of the valley.

Table I. Measured and dendrochronologically calibrated ${ }^{14} \mathrm{C}$ age of samples collected in the boreholes.

\begin{tabular}{ccccc}
\hline Sample Code & Borecore & Unit-Depth $(\mathrm{m})$ & Radiocarbon Age & Cal BP \\
\hline C1 & Sv7 & Al3-46.9 & $14110 \pm 70$ & $16840 \pm 400$ \\
C2 & Sv7 & Al3-41.5 & $12240 \pm 90$ & $14151 \pm 355$ \\
C3 & Sv7 & Al3-35.5 & $9600 \pm 70$ & $10915 \pm 245$ \\
C4 & Sv6 & Al3-35.5 & $10050 \pm 70$ & $11590 \pm 360$ \\
C5 & Sv6 & Al3-31.5 & $9310 \pm 70$ & $10440 \pm 200$ \\
C6 & Sv6 & T3-26.9 & $8020 \pm 70$ & $8810 \pm 210$ \\
C7 & Sv6 & T3-24.6 & $7660 \pm 60$ & $8400 \pm 60$ \\
C8 & Sv3 & T2-12.0 & $5040 \pm 70$ & $5755 \pm 155$ \\
C9 & Sv3 & T1-11.2 & $3450 \pm 60$ & $3695 \pm 145$ \\
\hline
\end{tabular}



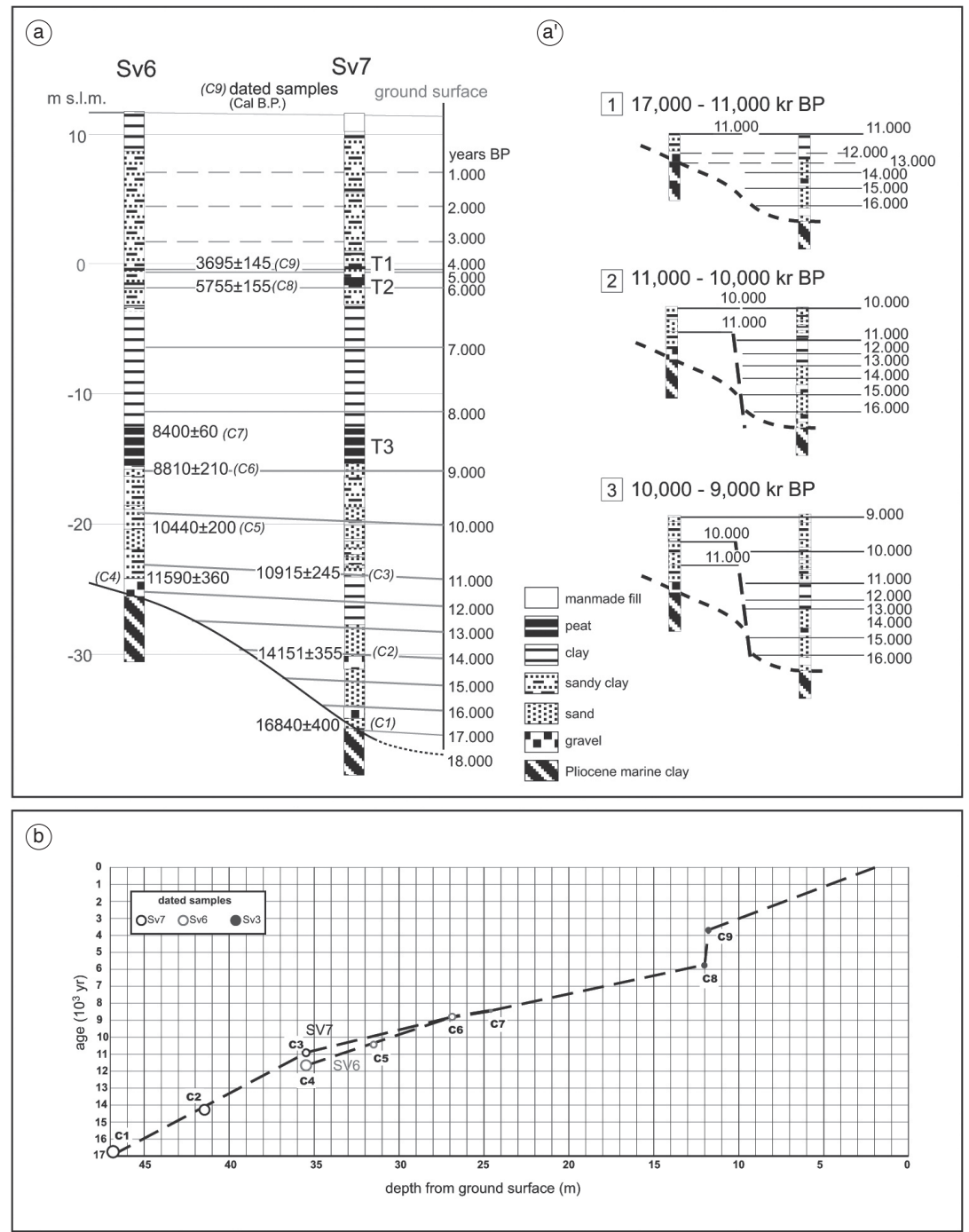

Fig. 7a,b. a) Detailed stratigraphy of boreholes Sv6 and Sv7 and lateral correlation of the horizontal isochrones (grey) based on the C14 age of dated samples (see table I). a') Palinspastic restoration of the inferred fault displacement, accounting for different elevation of the isochrones at the two boreholes. b) Sedimentation rate at the two boreholes estimated from the age of the dated samples (width of the circles is proportional to the variability associated with the sample age).

From a closer view, the Pleistocene gravel layer $\left(\mathrm{S}_{2 \mathrm{a}}\right.$ in fig. 5) records an abrupt vertical step between boreholes Sv2 and Sv3, evidencing a $\sim 4$ displacement affecting the substratum of the alluvial valley in only $\sim 14 \mathrm{~m}$ of linear distance. This gravel horizon marks the unconformity between the Pliocene substratum and the fluvio-lacustrine sequence of the Paleotiber (800 ka, Karner et al., 2001), and it is usually characterized by a sub-horizontal 
trend throughout the area of Rome (Marra and Rosa, 1995). Indeed, this gravel horizon was deposited $800 \mathrm{ka}$ throughout the alluvial coastal plain that extended to the present-day Ponte Galeria area (Marra et al., 1998; Florindo et al., 2007; Marra et al., 2008), where the same gravel horizon maintaining a horizontal attitude for several hundreds of meters is observable in numerous quarries that exploit it. Abrupt changes in elevation of this gravel horizon, as those inferred from the reconstructed cross-section in fig. 5, are possibly related to tectonic displacement. The base of the unit in the study area was expected to be at an elevation in the range of -10 to $-15 \mathrm{~m}$ b.s.l. (Marra and Rosa, 1995); a consistent elevation is recorded in our section at the Sv2 and A1 boreholes (-13 m, see fig. 5). In contrast, we found the gravel at diverse depths at Sv3, Sv4 and Sv5, where the cross-section discloses a vertical lowering of its base surface, for a total amount of $8 \mathrm{~m}$ toward the center of the valley (fig. 5). Acquired stratigraphic logs located on the opposite bank of the Grottaperfetta valley (A13-A15 in fig. 7) show that the base of the gravel horizon resumes a more regular trend at an elevation of about -15 b.s.l. Assuming an originally subhorizontal trend for the base of the gravel unit, its dislocation is interpreted in cross-section of fig. 5b as the effect of faulting (zone of deformation $\left.a, a^{\prime}, a^{\prime \prime}\right)$. A faint irregularity in the gradient of the bottom surface (thick blue line in fig. 5) is also observed between Sv2 and Sv3A. Combined with the observation of a thick peat layer that pinches out between the same two boreholes, this fact doesn't allow us to exclude that the activity of the hypothesized fault may have continued through Holocene times.

A second sharp variation in the gradient of the bottom surface of the valley occurs between Sv6 and Sv7, where a vertical step of about 10 meters in a horizontal distance of $16 \mathrm{~m}$ is observed. The sudden deepening of the bottom of the alluvial deposits is here interpretable as the cause of the apparent asymmetric shape of the valley, as inferred from the ambient noise measurement cross-section (see fig. $4 a, b$ ). This feature may be due to faulting, or a morpho- logic feature that the valley inherited from the würmian erosive phase. In any case, even if we consider the first possibility, the hypothetic fault responsible for offsetting the base surface of the alluvial valley stopped to be active after the deposition of the peat layer T3, whose top shows horizontal attitude between SV6 and Sv7 (fig. 5).

\subsection{Sedimentation rate}

In fig. $7 \mathrm{~b}$ we have plotted the measured ages of the samples collected within Sv3, Sv6 and Sv7 as a function of the sample depths and then we have estimated the sedimentation rates and the related isochrones for boreholes SV6 and SV7, respectively (fig. 7a,a'). In this way, we simply considered the average value of each radiocarbon age without the associated uncertainty (which can be evaluated from the width of the circles indicating the ages in fig. 7b). Also taking into account that sedimentation in a fluvial-lacustrine environment may occur discontinuously, the graphics of fig. 7 should be considered as merely indicative of the general trend and several observations are worth to be outlined. First of all, a slower sedimentation rate (corresponding to a lesser thickness of sediments) characterizes the time span 18-11 ka. A significant increase in the sedimentation rate occurs from $11 \mathrm{ka}$ (fig. 7a-b) up until $6 \mathrm{ka}$, when an abrupt change is disclosed, with an almost complete stop to sedimentation between $5 \mathrm{ka}$ and $4 \mathrm{ka}$. This latter sedimentary event corresponds to the deposition of the peat layers $\mathrm{T} 1$ and T2. No similar variation in the sedimentation rate is observed in correspondence of the deposition of the thicker peat layer T3. The time of deposition of the peat layers T1 and T2 corresponds to a well known phenomenon: around $6 \mathrm{ka}$ there is an abrupt slowing down in the global sea-level rise, which evidently corresponds to a sharp variation of the sedimentation rate within the hydrographic network of the Tiber River. In contrast, no global event is correlated to the time of deposition of the peat layer T3. We also point out that an increase in the velocity of the sea-level rise occurs around 14 ka (Melt Water Pulse 1A, Bard et al., 1996), 
whereas a variation (an increase) in the sedimentation rate is recorded in borehole Sv7 only since $11 \mathrm{ka}$ (fig. 7b).

A sub-horizontal attitude characterizes coeval sediments since about 9,000 yr BP. On the contrary, before this age a difference in elevation for coeval portions of the boreholes, and a general inclination towards the central axis of the valley is recorded. Consequently, the isochrones that we have reconstructed for the two boreholes in fig. 7a disclose a vertical shift that is consistent both with an onlap of the sediments on the flank of the incision, as well as with a fault dislocation, assuming a horizontal aggradation since the end of the last glacial maximum. In the second hypothesis, the «displacement» of the isochrones proportionally increases with depth (and thus with age: $1.2 \mathrm{~m}$ of displacement between the isochrones of $10,000 \mathrm{yr}$ $\mathrm{BP}$ and $2.4 \mathrm{~m}$ between the isochrones of 11,000 yr BP), in agreement with what expected for sinsedimentary fault activity. Palinspastic restoration of the cross-section in fig. 7a' shows that when the offset between the isochrones of $11,000 \mathrm{yr} \mathrm{BP}$ in the two boreholes is eliminated, we obtain a good chronologic and stratigraphic correlation of the two adjacent sedimentary sequences (fig. 7a' ${ }_{1}$ ). This fact allows us to hypothesize that no significant vertical movement occurred in the time span 17,000-11,000 yr BP. Successively, repeated instances of subsidence may explain: i) the steeper gradient of the base surface of the alluvial deposits observed between SV6 and SV7; ii) the thicker sedimentary succession observed in Sv7, filling the space created by faulting in the time span 11,000 9,000 yrs BP (fig. 7a' $2-3$ ). We point out that this would be in agreement with an increase in the sedimentation rate at borehole Sv7 after $11 \mathrm{kyr}$.

\subsection{Possible tectonic indications from the stratigraphic record}

Since lateral discontinuities commonly occur within fluvial sediments, we focused our attention just on those sectors where the vertical offsets affect all the stratigraphic limits, both the alluvial sediments and the underlying preHolocene substratum. In particular, it is worth to note that along the same vertical section can be observed an increasing displacement with depth. This is actually what expected in case of repeated faulting, although even in this case the occurrence of such features may not be univocally attributable to a fault displacement.

The peat accumulation originating $\mathrm{T} 3$ is significant, the thickness of the horizon ranging between $1.5 \mathrm{~m}$ to $2.85 \mathrm{~m}$ and extending continuously for more than $200 \mathrm{~m}$. It seems reliable that such accumulation of peat is related to local phenomena that disturbed the regular sedimentary filling process in this portion of the Grottaperfetta valley, establishing marshy conditions within the valley for a relatively long period. One possible cause for producing the accumulation of a thick peat horizon is the slow subsidence of the area which, in turn, may be interpreted as due to tectonic collapsing of this portion of the valley. Moreover, conditions suitable for generating a peat horizon require very shallow water table over a flat area. Consequently, the top of a peat horizon displays a tabular trend over large extensions: significant vertical displacements (in the order of several decimeters) among closely-spaced (in the order of ten meters) boreholes might be suggestive of dislocation subsequent to deposition. Based on this notion, the different elevation of the top of the T3 unit along the reconstructed section is tentatively interpreted in fig. $5 \mathrm{~b}$ as the effect of two faults between Sv3 and Sv6 ( $a^{\prime}, a^{\prime}$ in fig. $5 \mathrm{~b})$ that lowered this horizon toward the centre of the valley. This hypothesis is supported by the analogous offset observed on the horizontal trend of the base of the gravel layer of the Middle-Pleistocene succession within the bedrock of the fluvial incision, already interpreted as the possible effect of faulting in the previous paragraph. Conversely, no sharp change in the elevation of T3 unit is observed between Sv6 and Sv7, excluding any activity after $8,800 \mathrm{yr}$ $\mathrm{BP}$ for the hypothesised fault affecting the contour of the fluvial incision in this area (zone of deformation $b$ in fig. 5b), and suggesting a possible southward migration of the fault activity.

The clay deposit overlying the T3 peat layer is quite uncommon within the sedimentary filling of the fluvial channels of the Tiber River and of its tributaries. It is constituted by a light 
blue-grey, very fine-grained deposit characterized by high plasticity and very low consistency. The presence of this $8 \mathrm{~m}$-thick stratum could be strictly related to the observed settlement that affected the buildings in this area. We speculate whether the origin of this extremely unconsolidated layer may be due to fast local sedimentation rate, induced by tectonic subsidence of the south-western portion of the Grottaperfetta valley.

The contact between the alluvial units $\mathrm{Al} 2$ and Al1 has a «spoon shaped» contour with maximum depth in correspondence of Sv5 (fig. 5 ). The same characteristic is recorded by the peat horizons $\mathrm{T} 1$ and $\mathrm{T} 2$ within Al1, with consequent increase of the thickness of the clay layer in between, as recorded in Sv5. This would suggest a shifted depocenter of the valley toward the southern edge, with respect to that inferred from the maximum depth and thickness of the oldest peat horizon T3 in Sv6 (fig. 5). Such migration would be in agreement with the hypothesis that after about 9 ka (age of T3) the deposition was influenced by a structural control of a single or multiple faults (a-a" in fig. 5b) in proximity of the southern edge of the valley that produced the lowering of this sector and the migration of the fluvial axis. A significant datum is that the change in depth of the most recent peat horizons (T1) corresponds to the strong discontinuity affecting the old substratum where the Middle-Pleistocene gravel layer displays an offset of about $4 \mathrm{~m}$, and with the anomaly of the gradient of the alluvial valley contour previously discussed. An additional observation is that the amount of vertical displacement recorded by the sequence increases with depth. The oldest horizons are more displaced than the younger (as outlined in fig. 8a). This is what can be expected following a long-term activity of a fault. The oldest units experienced more events of deformation respect to the overlying units which are less deformed. It is also worth of note that the electrical profiles evidenced a lateral discontinuity in the stratigraphy in between Sv2 and Sv3 (see also fig. 8a). A further observation is the attitude of three sandy gravel intercalations, 3 to $10 \mathrm{~cm}$ thick, recovered in Sv2, Sv3 and So1. Their lateral correlation displays a sub-horizon- tal attitude, but with small vertical displacements between $\mathrm{Sv} 2$ and $\mathrm{Sv} 3$, analogous to those observed in the peat stratum below (fig. 8a). Moreover, these three coarse grained layers between So1 and Sv2 gently dip towards SW, opposite to the general NE dipping trend of the sedimentary boundaries within the alluvial body, a fact that is consistent with a relative uplift occurring at the hanging-wall of the hypothesized fault.

\subsection{Identification and sampling of the hypothesized fault}

Based on all the above mentioned considerations, we attempted to recover the upward extension of the hypothetically traced fault plane in the zone of deformation $a$ in fig. 5 b by means of an inclined borehole. An oblique, $\mathrm{N} 225^{\circ}$ striking, $15^{\circ}$ inclined with respect to the vertical axis borehole (So1) was drilled between Sv2 and Sv3 (fig. 8a,b). This oblique borehole recovered at $5.3 \mathrm{~m}$ (corresponding to $5.1 \mathrm{~m}$ below the ground surface) a cemented, 7 $\mathrm{cm}$-thick, granular layer (fig. 8b,c). The layer is a breccia composed of well classed, mm-sized, black scoria clasts deriving from reworking of the pyroclastic rocks that constitute the principal outcropping units in the area of Rome. However, no clay matrix but carbonatic cement is present in this layer, suggesting a non-sedimentary genesis. It shows an inclination of $35^{\circ}$ with respect to the vertical axis of the borehole, corresponding to a maximum inclination of $20^{\circ}$ with respect to the vertical plane in the case it dips opposite to the borehole (as in the hypothesis of a NW-SE striking fault plane), and to a minimum inclination of $50^{\circ}$ in the case it dips parallel to the borehole. Even this lower value of inclination is incompatible with a sedimentary origin of this granular layer. In fact, the granular layer is embedded within the reddishbrown silty clay deposit of Al1 unit, which is characterized by sub-horizontal attitude of the strata. This peculiar layer does not occur in any other boreholes among those performed for this study, nor is a layer with similar lithologic features described in any stratigraphic log among the many we have analyzed. 

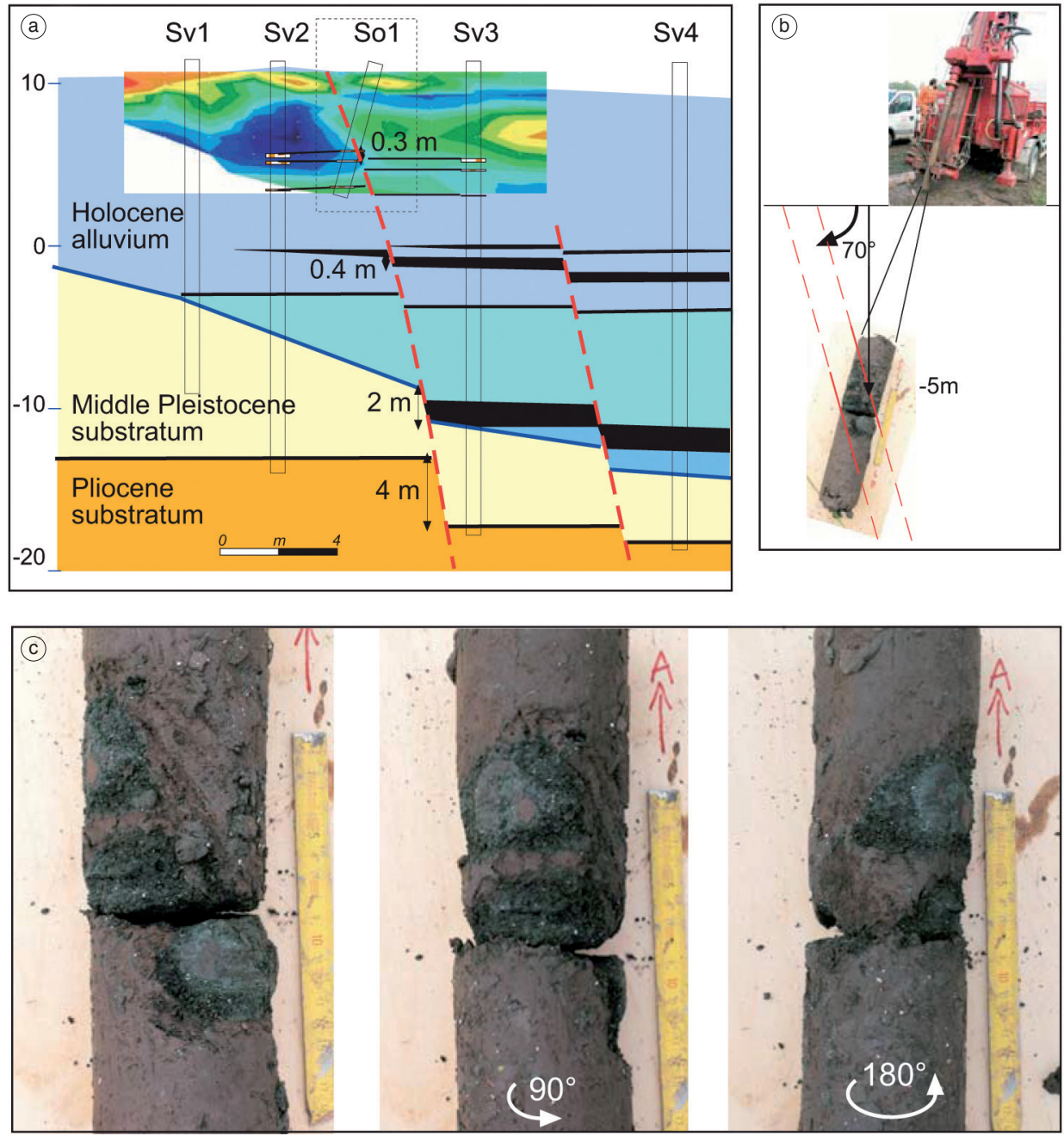

Fig. 8a-c. a) Cross-section showing the location of the oblique borehole So1, the detail of the interpreted stratigraphy, and the geoelectric tomographic profile, in correspondence of the hypothesized fault zone between Sv2 and Sv3. b) Position of the borehole So1 containing the breccia layer matching the hypothesized fault trace (dashed red lines) is shown. c) Detail of the borecore showing different perspective views of the recovered breccia stratum.

When the maximum possible inclination of $70^{\circ}$ from the horizontal for the peculiar granular layer is reported in the cross-section (fig. 8a), a good fit is observed with the location and inclination of the resistivity discontinuity evidenced by the geoelectrical profile.

A possible interpretation is that the inclined granular layer represents the filling of a tension crack induced by differential settlement of the surrounding clayey sediment. However, it is worth of notice that the location of this hypothetical discontinuity plane is strictly consistent with the position of the fault trace independently inferred from the geomorphologic study of the Grottaperfetta valley (fig. 2). 


\section{Final interpretation}

It is our opinion that the presence of the coarse layer, combined with the above mentioned stratigraphic indications of possible strata displacement, indicates that a faulting process affected the sedimentary filling of the valley. This process does not necessarily have to be seismic; surface faulting may also accompany aseismic creep or natural or man-induced subsidence. Hence, our hypothesis is not in contrast with that used by others to explain the damage suffered by the buildings in the area (conjunction of inadequate foundation and differential settlement of soft sediments).

A fault system like that hypothesized in fig. 2 is able to originate a graben-like, subsiding sector, where lacustrine and palustrine sedimentary condition allowed for the deposition of the T3 peat level and the overlying Al 2 clay layer. The presence of this very poorly consolidated clay layer should be regarded as the principal element for inducing the peculiarly high soil settlement observed within the Grottaperfetta Valley (Stramondo et al., 2008). Moreover, sin-sedimentary tectonics may account for the observed sharp lateral variation of the thickness of the alluvial deposits. Finally, the occurrence of a fault discontinuity in the position inferred by this study, enhancing differential settlement, is consistent with the location of the most damaged buildings, as shown in fig. 3 .

Lack of historical records of large seismicity within the City of Rome (Molin and Guidoboni, 1989) implies that the faulting process would be characterized by an aseismic behaviour, therefore, excluding the occurrence of associated earthquakes. Another possibility is that the inferred displacement occurred as minor slippage along a «loosened» fault, during ground shaking associated with earthquakes in the neighbourhoods.

Based on all the abovementioned inferences, we considered performing a trench excavation to verify the hypothesis that a fault affected the Holocene sediments of the valley. However, the local authority has been reluctant to use a falsification method to dispel the doubts, preferring to consider the illustrated stratigraphic setting incompatible with the presence of faulting proc- esses, but the result of sedimentary processes. This fact eventually testifies the difficulty of continuing such investigations in urbanized areas, not only for the logistic hindrance, but also for those of an economic and social nature.

\section{Conclusions}

A multidisciplinary study including geomorphological investigations, geoelectric and closely-spaced borehole surveys of a portion of the Grottaperfetta alluvial valley in Rome was carried on to verify the hypothesis that faulting processes may affect the Late PleistoceneHolocene alluvial sequence in that area.

In summary our research at this site reports that:

- geomorphology of the alluvial valley is suggestive of a recent evolution of the stream course, that appears structurally controlled by a system of NW-SE oriented faults;

- lateral discontinuity of the stratigraphic limits within the alluvial sequence are coupled to analogous discontinuity affecting the older strata in the substratum of the valley;

- vertical displacements of the stratigraphic limits between adjacent boreholes show increasing amount of dislocations with depth;

- a variation of the electrical resistivity of the terrains is observed between the two boreholes (Sv2 and Sv3) in which the evidence of systematic vertical displacements between the stratigraphic limits is stronger;

- an oblique borehole was performed aimed at intersecting the inferred fault between Sv2 and Sv3. It recovered a cemented breccia layer, $7 \mathrm{~cm}$ thick, whose location and geometry are consistent with the hypothesised fault gauge;

- the location of the sampled fault zone matches the trace of the NW-SE trending fault that was independently inferred from geomorphologic study of the area.

Although each of the mentioned elements may be individually originated by a non-tectonic process, we believe that their concomitance and the lack of negative evidence, support the hypothesis that a faulting process influenced the Holocene deposition of the Grottaperfetta 
valley in a time as young as 1500 years (inferred $\mathrm{C} 14$ age of the deposit at $-5 \mathrm{~m}$ from the ground surface, fig. 7a). We therefore judge mandatory the excavation of a trench to verify the faulting hypothesis.

\section{Acknowledgements}

This work was funded by the Ufficio Extradipartimentale di Protezione Civile del Comune di Roma (Department of Civil Protection of Rome). Special thank go to Patrizia Cologgi. We are also grateful to Pasquale Ladogana. Marco Marchetti kindly performed the portable GPS topographic survey for borehole elevation. CONGEO srl carried out the drilling campaign. We wish to thank Pietro Nigro, Anna Maria Bruna and Acqua Marcia srl for kindly providing additional stratigraphic data.

\section{REFERENCES}

Bard, E., B. Mahelin, M. Arnold, L. Montaggioni, G. CABIOCH, G. FAure and F. Rougerie (1996): Deglacial sea-level record from Tahiti corals and the timing of global meltwater discharge, Nature, 382, 241-244.

Bozzano, F., R. Funiciello, F. Marra, A. Rovelli and G. VALENTini (1995): Il sottosuolo dell'area dell'Anfiteatro Flavio in Roma, Geologia Applicata e Idrogeologia, 30, 405-422.

Bozzano, F., A. Andreucci, M. Gaeta and R. Salucci (2000): A geological model of the buried Tiber River valley beneath the historical centre of Rome, Bull. Eng. Geol. Env., 59, 1-21.

Caputo, C., M. Del Monte, P. Fredi, E. Lupia Palmieri and F. Pugliese (1995): Geomorphological Features, The Volcano of the Alban Hills, edited by E. TrigiLA, (Università degli Studi, «La Sapienza», Roma), 13-32.

Florindo, F., D.B. Karner, F. Marra, P.R. Renne, A.P. ROBERTS and R. WEAVER (2007): Radioisotopic age constraints for glacial terminations IX and VII from aggradational sections of the Tiber River delta in Rome, Italy, EPSL, 256, 61-80.

KARNER, D.B. and F. MARRA (1998): Correlation of Fluviodeltaic Aggradational Sections with Glacial Climate History: A Revision of the Classical Pleistocene Stratigraphy of Rome, Geol. Soc. Am. Bull, 110, 748-758.

KARNER, D.B. and P.R. RENNE (1998): 40Ar/39Ar geochronology of Roman Volcanic Province tephra in the Tiber River Valley: Age calibration of middle Pleistocene sea-level changes, Geol. Soc. Am. Bull., 110, $740-747$.

Karner, D.B., F. Marra, F. Florindo and E. Boschi (2001): Pulsed uplift estimated from terrace elevations in the coast of Rome: Evidence for a new phase of vol- canic activity?, Earth Planet. Sci. Lett., 188, 135-148.

LoCARDI, E., G. LOMBARDI, R. Funiciello and M. PAROTTO (1977): The main volcanic groups of Latium (Italy): relations between structural evolution and petrogenesis, Geologica Romana, 15, 279-300.

Marra, F. and C. Rosa (1995): Stratigrafia e assetto geologico dell'area romana, in La Geologia di Roma. Il Centro Storico, (Volume Speciale delle Mem. Descr. Carta Geol. d'It., a cura di R. Funiciello), 50, 49118.

Marra, F., F. Florindo and D.B. Karner (1998): Paleomagnetism and geochronology of early Middle Pleistocene depositional sequences near Rome: comparison with the deep sea $¥ 180$ climate record, Earth and Planetary Science Letters, 159, 147-164.

MARRA, F. (1999): Low-magnitude earthquakes in Rome: structural interpretation and implications for local stress-field, Geoph. Journ. Int., 138, 231-243.

MARRA, F. (2001): Strike-slip faulting and block rotation: a possible triggering mechanism for lava flows in the Alban Hills?, J. of Struct. Geol., 23 (1), 127-141.

Marra, F., J. Taddeucci, C. Freda, W. Marzocchi and P. SCARLATO (2004a): The recurrence of volcanic activity along the Roman Comagmatic Province (Tyrrhenian margin of Italy) and its tectonic significance, Tectonics, 23, TC4013, doi: 10.1029/2003TC001600.

Marra, F., P. Montone, M. Pirro and E. Boschi (2004b): Evidence of Active Tectonics on a Roman Aqueduct System (II-III Century A.D.) near Rome, Italy, J. of Struct. Geol., 26, 679-690.

Marra, F., F. Florindo and E. Boschi (2008): The history of glacial terminations history from the Tiber River (Rome): insights to glacial forcing mechanisms, Paleoceanography, 23, doi: 10.1029/2007PA001543.

Martino, S., F. Bozzano, A. Caserta and F. Marra (2004): Il sito sperimentale di Valco S.Paolo (Roma): caratterizzazione geotecnica statica e dinamica dei depositi alluvionali del Tevere, (Convegno GNGTS, Ottobre 2004, CNR, Roma).

Mc Calpin, J. P. (Ed.) (1996): Paleoseismology. (Elsevier).

Molin, D. and E. Guidoboni (1989): Effetto fonti, effetto monumenti a Roma: i terremoti dell'antichità a oggi, in $I$ Terremoti prima del Mille in Italia e nell'Area Mediterranea, edited by F. Guidoboni, (S.G.A., Bologna), 194-223.

Montone, P., A. Amato, C. Chiarabba, G. Buonasorte and A. FIORDELISI (1995): Evidence of active extension in Quaternary volcanoes of Central Italy from breakout analysis and seismicity, Geophys. Res. Lett., 22, 19091912.

NAKAMURA, Y. (1989): A method for dynamic characteristics estimation of subsurface using microtremor on the ground surface, QR of R.T.R., 30, 1, February.

SERRI, G. (1997): Neogene-Quaternary magmatic activity and its geodynamic implications in the Central Mediterranean region, Ann. Geof., 3, 681-703.

Stramondo, S., F. Bozzano, F. Marra, U. Wegmuller, F.R. Cinti, M. Moro and M. SARoli (2008): Subsidence Induced by Urbanisation in the City of Rome detected by Advanced InSAR Technique and Geotechnical Investigations, Remote Sensing of Environment, 112, 3160-3172.

(received November 29, 2007; accepted September 1, 2008) 